\title{
Effect of the Reduction Temperature of PdAg Nanoparticles during the Polyol Process in the Ethanol Electrooxidation Reaction
}

\author{
R. Carrera-Cerritos, ${ }^{1}$ C. Salazar-Hernandez, ${ }^{1}$ \\ I. R. Galindo-Esquivel, ${ }^{2}$ and R. Fuentes-Ramirez $\mathbb{D}^{2}$ \\ ${ }^{1}$ Departamento de Formación Profesional Genérica, Unidad Profesional Interdisciplinaria de Ingeniería Campus Guanajuato, \\ Instituto Politécnico Nacional, Col. Fracc. Industrial Puerto Interior, 36275 Silao de la Victoria, GTO, Mexico \\ ${ }^{2}$ Departamento de Ingeniería Química, Universidad de Guanajuato, Noria Alta S/N, 36050 Guanajuato, GTO, Mexico
}

Correspondence should be addressed to R. Fuentes-Ramirez; rosalba@ugto.mx

Received 28 September 2017; Revised 15 January 2018; Accepted 30 January 2018; Published 13 March 2018

Academic Editor: Philippe Knauth

Copyright (C) 2018 R. Carrera-Cerritos et al. This is an open access article distributed under the Creative Commons Attribution License, which permits unrestricted use, distribution, and reproduction in any medium, provided the original work is properly cited.

\begin{abstract}
This work reports the effect of reduction temperature during the synthesis of PdAg catalysts through the polyol process and their evaluation in the ethanol electrooxidation reaction (EOR). The characterization was performed using Transmission Electron Microscopy (TEM) and X-Ray Diffraction (XRD). The electrochemical evaluation for the ethanol electrooxidation reaction was implemented in alkaline medium using chronoamperometry (CA) and cyclic voltammetry (CV). An important effect of the reduction temperature on electroactivity and catalytic stability was observed: both the maximum current density and the catalytic stability were higher in the catalyst synthesized at the highest temperature $\left(135^{\circ} \mathrm{C}\right)$. This performance was associated with the extent of the interaction between $\mathrm{Pd}$ and $\mathrm{Ag}$ which was measured in terms of the structural expansion of $\mathrm{Pd}$.
\end{abstract}

\section{Introduction}

Researchers concerned in current environmental pollution problems and the depletion of fossil fuels have found interest in new sources of renewable and clean energy. Ethanol is an alcohol with high energy density $(8 \mathrm{KW}-\mathrm{h} / \mathrm{kg})$, which can be renewable if obtained from biomass. Ethanol is also nontoxic and has characteristics that allow it to be stored and transported easily and safely [1]. These properties make ethanol an attractive power source for fuel cells used to produce electricity for mobile devices and transport applications $[2,3]$. However, the ethanol electrooxidation reaction (EOR) that occurs at the anode has slow kinetics in the catalysts currently used, so the development of anodic materials with high electroactivity and stability is still a challenge $[4,5]$.

Among the pure elements, palladium has been identified as the most suitable catalyst for the EOR in alkaline solutions due to its high activity and stability during the reaction $[6,7]$. For this reason, several attempts have been made to improve its catalytic performance through a combination with other elements, since bimetallic and multimetallic catalysts synthesized at nanoscale contribute to the enhancement of the catalytic activity [8-10]. A criterion usually used to qualitatively determine surface reactivity is the use of the $d$-band center. According to this model, a shift in the position of the $d$-band center towards the Fermi level indicates an improvement in the chemisorption properties, which are then associated with the reactivity of the material. The Density of States (DOS) for the $d$-band of the metal varies from metal to metal, and it can be modified by several factors such as ligand and geometric effects. This then leads to a variation of the electronic properties of the metal. According to Hammer and Nørskov calculation, the center of the $d$-band of Pd ( $3.89 \AA)$ will shift when combined with $\mathrm{Ag}(a=4.09 \AA)$ [11]. As a result, and because silver is a much cheaper and abundant metal than Pd, the bimetallic nanoparticles of PdAg are receiving great attention. These materials may be able to potentiate various reactions such as Oxygen Electro-Reduction and the electrooxidation of small chain alcohols [12, 13]. 
The polyol method is a very fast method that does not require extreme conditions or sophisticated equipment and can be scaled up to produce larger amounts of nanoparticles. Due to these properties, this method has been used for the synthesis of many metal nanoparticles. In fact, the polyol method has been extrapolated for the synthesis of PdAg nanoparticles of different shapes and sizes [14, 15]. The evaluation of the PdAg nanoparticles as catalysts for EOR in alkaline medium has shown that the synergistic interaction between the $\mathrm{Pd}$ and $\mathrm{Ag}$ atoms not only produces materials that exhibit excellent catalytic activity but also promotes tolerance towards the adsorbed $\mathrm{CO}$, thus improving the catalytic stability during EOR [16]. However, the activation energy for the EOR reaction has not been sufficiently reduced $[17,18]$. In addition, the effect of alloy grade and particle size on the catalytic activity has not been explored in detail. Considering the above, interesting catalytic properties could be inferred when manipulating the temperature of reduction during the polyol process in order to modify the degree of interaction between the palladium and the silver. Thus, the synthesis of the PdAg nanoparticles supported on carbon vulcan at three different temperatures was performed. The catalysts were characterized by TEM and XRD. Also, the electrocatalytic activity of the nanoparticles in the EOR was evaluated in alkaline solutions using $\mathrm{CV}$ and CA.

\section{Materials and Methods}

2.1. Synthesis of PdAg Catalysts. The previously reported polyol method to obtain pure Pd-based nanobars was modified in order to obtain bimetallic nanoparticles of PdAg [14, 15]. This process is described as follows: $5 \mathrm{ml}$ of ethylenglycol (EG, 99.9\%, J.T. Baker) were added to a $25 \mathrm{ml}$ three-necked flask coupled to a reflux system. The flask was then heated to $105^{\circ} \mathrm{C}$ (PdAg-a), $120^{\circ} \mathrm{C}(\mathrm{PdAg}-\mathrm{b})$, and $135^{\circ} \mathrm{C}(\mathrm{PdAg}-\mathrm{c})$ with constant stirring. Two solutions were prepared separately: (1) $0.0486 \mathrm{~g}$ of $\mathrm{Na}_{2} \mathrm{PdCl}_{4}$ (98\%, Sigma-Aldrich) and $0.6 \mathrm{~g}$ of $\mathrm{KBr}$ (99\%, Sigma-Aldrich) were dissolved in $1 \mathrm{ml}$ of deionized water, and (2) $0.0916 \mathrm{~g}$ of PVP (99\%, Sigma-Aldrich) and $0.005 \mathrm{~g}$ of $\mathrm{AgNO}_{3}$ (99\%, Sigma-Aldrich) were added in $3 \mathrm{ml}$ of EG. The solution with the Pd precursor (1) was added to the three-necked flask and, after three minutes, the silver solution (2) was incorporated. The mixture was allowed to react for $1 \mathrm{~h}$ at a fixed temperature. Vulcan at a ratio $20 / 80 \mathrm{Pd} / \mathrm{C}$ was added during the reaction; this support was preheated at $277^{\circ} \mathrm{C}$ for $3 \mathrm{~h}$. At the end of the reaction time, the product was cooled down to room temperature. Subsequently, it was separated by centrifugation with acetone (99.9\%, JT Baker) and then washed with deionized water 8 to 10 times. The speed used for the first separation was $4000 \mathrm{rpm}$, while $60000 \mathrm{rpm}$ was used for rinsing. Finally, the product was dried at $100^{\circ} \mathrm{C}$ for $12 \mathrm{~h}$.

2.2. Catalyst Characterization. The visualization of the synthesized nanoparticles was carried out in a JEOL Transmission Electron Microscope, model JEM-1010 equipped with a tungsten filament. It was operated with $80 \mathrm{kV}$ and a magnification of 200000x. The microscope has a model ORIUS digital camera and was operated with the GATAN software.
The crystallinity of the catalysts was analyzed in powder using a Rigaku Miniflex instrument. The radiation emitted by the $\mathrm{X}$-ray tubes of this diffractometer corresponded to the $\mathrm{Cu}$ $\mathrm{K} \alpha(1.5406 \AA)$. The patterns were collected from $2 \theta=5$ to $80^{\circ}$, with a step of $0.02^{\circ}$, and a count time of $0.06 \mathrm{~s}$ per point. The experimental data of the $\operatorname{Pd}(200)$ reflection was fitted to a Gaussian distribution using the OriginPro 9 software. In all cases, the coefficient of determination ( $R$-square) was higher than 0.95. The center maximum and the FWHM were obtained from the adjusted peak to perform the calculations of lattice parameter and crystal size.

2.3. Electrochemical Characterization. The electrochemical analysis was done in a model SP-150 Biologic Science Instruments potentiostat/galvanostat controlled by a Ec-Lab Software (V10.19) and a cell of three electrodes. A saturated calomel electrode (SCE) was used as the reference electrode, while a platinum electrode was used as the counterelectrode. The working electrode consisted of a glassy carbon disc which was previously polished with alumina powder $(0.05 \mu \mathrm{m})$, then sonicated for 10 minutes, and washed with deionized water. For the electrochemical measurements, a mixture of $1.0 \mathrm{mg}$ of the electrocatalyst and $73 \mu \mathrm{l}$ of isopropyl alcohol (99\%, J.T. Baker) was prepared by sonication for 20 minutes. Then, $7 \mu$ l of Nafion ${ }^{\circledR}$ solution (5\% isopropyl alcohol, SigmaAldrich) was added to the mixture and sonicated for 20 minutes in order to obtain a homogeneous ink. $2.2 \mu \mathrm{l}$ of the catalyst ink was placed on the working electrode. Then, it was dried using air at room temperature to obtain a thin film of catalyst. Cyclic voltammetry was carried out in an aqueous solution of $1 \mathrm{M} \mathrm{KOH} \mathrm{(98 \% ,} \mathrm{Sigma-Aldrich)} \mathrm{with} \mathrm{and}$ without $1 \mathrm{M}$ ethanol (99\%, J.T. Baker). A potential window from -1 to $0.4 \mathrm{~V}$ (versus SCE) was scanned at $0.05 \mathrm{Vs}^{-1}$. Chronoamperometry measurements were performed in an aqueous solution of $1 \mathrm{M} \mathrm{KOH}$ with $1 \mathrm{M}$ ethanol at a potential of $-0.3 \mathrm{~V}$ (versus SCE) for $2400 \mathrm{~s}$.

\section{Results and Discussion}

3.1. Synthesis of PdAg Catalysts. Figure 1 shows the micrographs of the three synthesized catalysts. A mixture of square and spherical nanoparticles of different sizes was obtained in the three temperatures. The appearance of nanobars was expected because the technique used in this work is a modification of the one used by our work group to obtain PdAg nanobars [15].200 PdAg nanoparticles of both spheroidal and rectangular shapes were measured and percentage frequency was calculated. The formation of PdAg nanobars was $29.5 \%$, $15.5 \%$, and $17.5 \%$ for the PdAg-a, PdAg-b, and PdAg-c catalysts, respectively. The average size (width $\times$ length, $\mathrm{nm} \times \mathrm{nm}$ ) for the PdAg-a catalyst was $5 \times 15,10 \times 30$ for PdAg-b, and $10 \times$ 40 for PdAg-c. It was observed that the percentage frequency of nanobars in the three catalysts was low in comparison to other reports $[15,25,26]$. This result was associated with (a) the lower amount of water used in this work, which decreases the molding of the nanoparticle through oxidative etching and (b) the high reaction temperatures that speed up the reduction kinetics of the precursors. The combination of these conditions provides a stronger reduction environment 

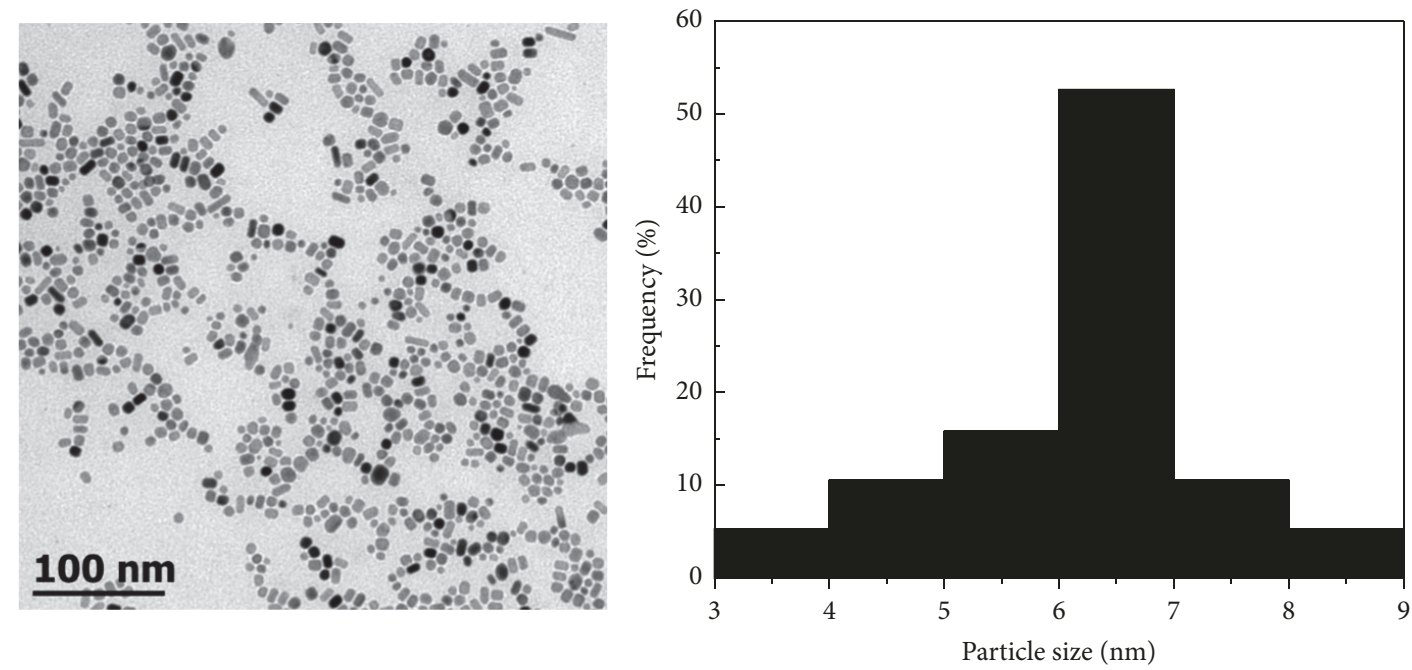

(a)
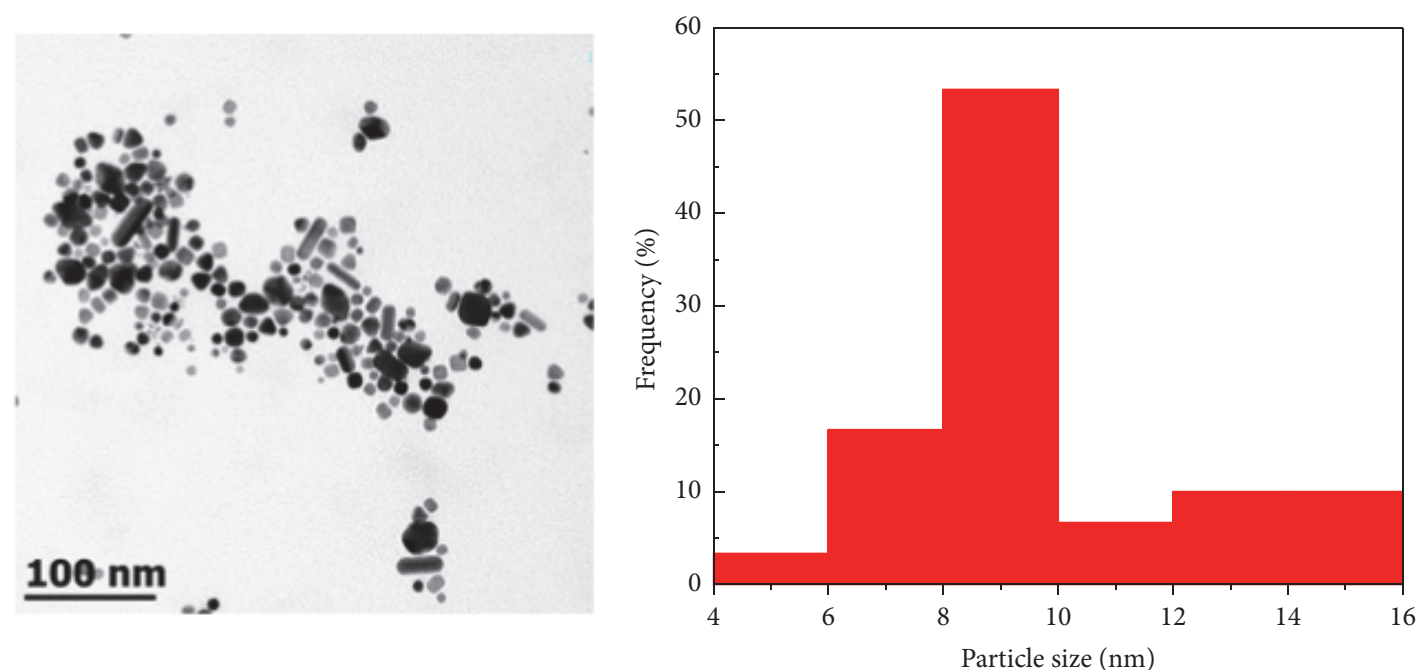

(b)
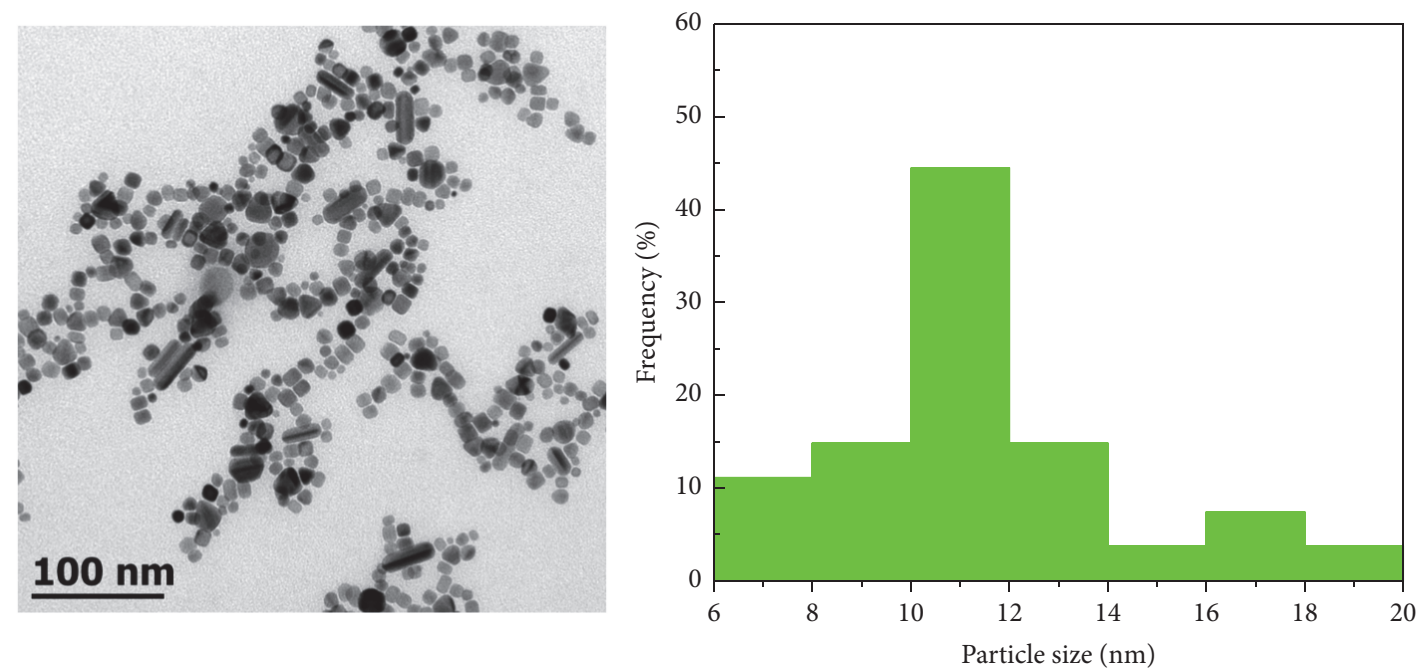

(c)

FIgURe 1: TEM micrographs and particle size distribution for (a) PdAg-a, (b) PdAg-b, and (c) PdAd-c catalysts. 


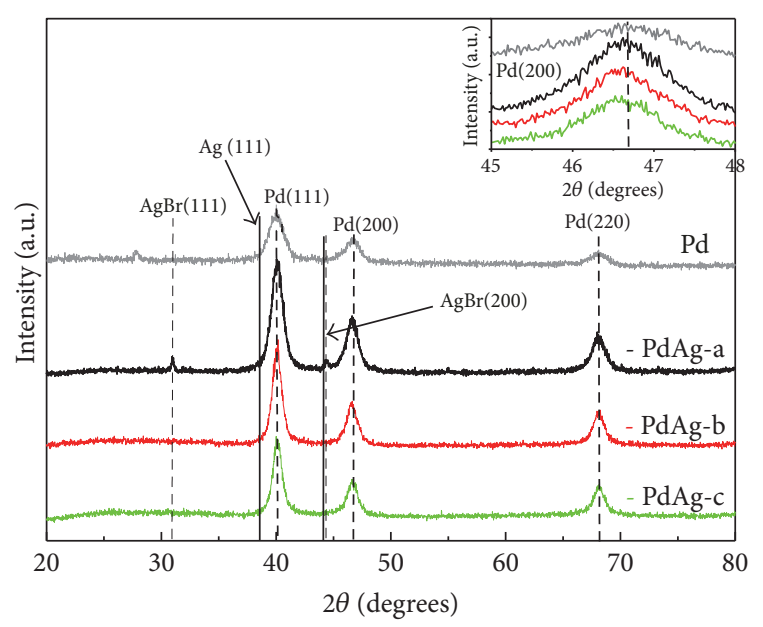

FIGURE 2: XRD patterns for the catalysts and their comparison with a pure Pd catalyst.

that favors the morphological transformation from a nanobar towards a spheroidal nanoparticle $[15,25,26]$. Figure 1 also shows the spheroidal nanoparticle size distributions. A monomodal and narrow size distribution was observed for the PdAg-a and PdAg-c catalysts, while the PdAg-b catalyst displayed a bimodal and wide size distribution. The mean sizes of 6.2, 9.7, and $11.3 \mathrm{~nm}$ correspond to the catalysts PdAga, PdAg-b, and PdAg-c, respectively. This result showed that the mean particle size increased with the increase of the reduction temperature during the polyol process.

Figure 2 shows the diffractograms for the PdAg-a, PdAgb, and PdAg-c catalysts. An XRD pattern of a Pd catalyst was also plotted as a reference. In the aforementioned pattern, the characteristic planes of $\operatorname{Pd}\left(\begin{array}{lll}1 & 1 & 1\end{array}\right),\left(\begin{array}{lll}2 & 0 & 0\end{array}\right)$, and $\left(\begin{array}{lll}2 & 2 & 0\end{array}\right)$ were observed at angles of $40.1,46.6$, and $68.1^{\circ}$, respectively (Card JCPDS 46-1043 for Pd, long dash lines). These XRD reflections are similar to those observed in the PdAg catalysts, indicating that they have a face-centered cubic structure. Additionally, reflections corresponding to $\mathrm{AgBr}$ (Card JCPS 06-0438 for $\mathrm{AgBr}$, dotted lines) were distinguished in the $\mathrm{PdAg}$-a catalyst. These reflections of impurities were due to softer reduction conditions constituted by the lower reaction temperature that does not act in favor of the reduction of the $\mathrm{AgBr}$. This compound has a more negative reduction potential than the rest of the $\mathrm{Pd}$ and $\mathrm{Ag}$ species in the reaction mixture $[14,15]$. Therefore, the reaction temperature used to obtain the PdAg-b $\left(120^{\circ} \mathrm{C}\right)$ and PdAg-c $\left(135^{\circ} \mathrm{C}\right)$ catalysts was sufficient to hinder the formation of $\mathrm{AgBr}$ crystals.

Regarding the pure Pd pattern, a slight shift towards lower angles was observed in the PdAg-a, PdAg-b, and PdAg-c catalysts. This angular shift was associated with the expansion of the palladium crystalline lattice due to the inclusion of $\mathrm{Ag}$ atoms with atomic radius greater than that of $\mathrm{Pd}$ (see lattice parameters in Table 1). The angular shift is more noticeable in the zoomed in graph between 45 and $48^{\circ}$ that shows the $\operatorname{Pd}\left(\begin{array}{lll}2 & 0 & 0\end{array}\right)$ reflection. The absence of reflections in the pure$\mathrm{Ag}$ angles (solid lines of the diffraction pattern) suggests that the Ag was integrated in the crystalline Pd network. This avoids the formation of silver-rich regions detectable by XRD.
TABLE 1: Structural parameters obtained from XRD for the PdAg-a, PdAg-b, and PdAg-c catalysts.

\begin{tabular}{lcc}
\hline Electrocatalyst & $\begin{array}{c}\text { Crystal size }(200) \\
(\mathrm{nm})\end{array}$ & $\begin{array}{c}\text { Lattice } \\
\text { parameter } a \\
(\mathrm{~nm})\end{array}$ \\
\hline Pd & 7.3 & 0.3846 \\
PdAg-a & 6.8 & 0.3891 \\
PdAg-b & 7.3 & 0.3892 \\
PdAg-c & 7.6 & 0.3898 \\
\hline
\end{tabular}

A gradual increase in angular displacement was observed while elevating the reaction temperature. This is indicative of a higher degree of alloying between $\mathrm{Pd}$ and $\mathrm{Ag}$ when the temperature is elevated during the polyol process. Similar angular shifts have been reported in the literature, which have been obtained by increasing the concentration of the silver precursor in the PdAg system during reduction with hydrogen gas [18].

The average crystal size was calculated using the Full Width at Half Maximum of the peak (2 00$)$ and the Scherrer equation [18]. The results are shown in Table 1. A discrepancy between the sizes obtained by XRD and TEM techniques was observed since the TEM particle size is greater than that calculated by XRD. This difference between particle and crystal size indicates that the nanoparticles in the catalysts have a polycrystalline structure.

3.2. Electrochemical Characterization. Figure 3 shows the voltammograms for the PdAg-a, PdAg-b, and PdAg-c catalysts in $1 \mathrm{M} \mathrm{KOH}$ at room temperature. Four regions were observed in the anodic scan (Figure 3(a)). The first region at potentials lower than $-0.7 \mathrm{~V}$ (versus SCE) was associated with the desorption of hydrogen from the catalyst surface (region I). The second region, (II) from -0.7 to $-0.2 \mathrm{~V}$, was assigned to the formation of palladium hydroxides. The peaks observed in regions III and IV $(-0.2$ to $0.4 \mathrm{~V})$ were related to the palladium and silver oxidation, respectively [14]. The inverted processes were observed in the cathodic direction: the adsorption of hydrogen appeared at potentials near $-0.8 \mathrm{~V}$, while the reduction of palladium oxide to $\mathrm{Pd}^{0}$ and the reduction of silver oxide (peaks III and IV) were observed at -0.34 and $0.03 \mathrm{~V}$, respectively. The voltammogram in Figure 3(a) suggests that a high amount of Ag may be at the surface in the PdAg-a electrocatalyst. On the other hand, the weak signal in region IV for the PdAg-b and PdAg-c catalysts suggests that the surface of the nanoparticles is poor in $\mathrm{Ag}$ atoms. These results complement the observations made with $\mathrm{XRD}$ and indicated that Ag atoms PdAg-b and PdAg-c did not remain on the surface or in crystalline agglomerates in the form of $\mathrm{AgBr}$. As a consequence, the $\mathrm{Ag}$ atoms were properly integrated into the Pd structure in the catalysts that were synthesized at higher temperatures.

Figure 3 shows the evolution of the peaks' intensity of the electrocatalysts during the first ten cycles. An increase in the intensity of the hydrogen adsorption-desorption, hydroxyl, 


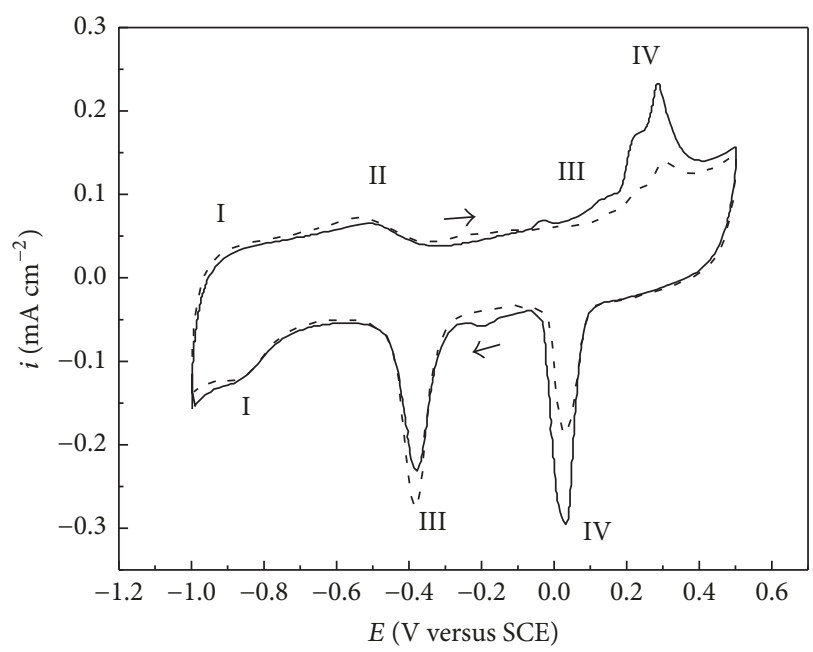

(a)

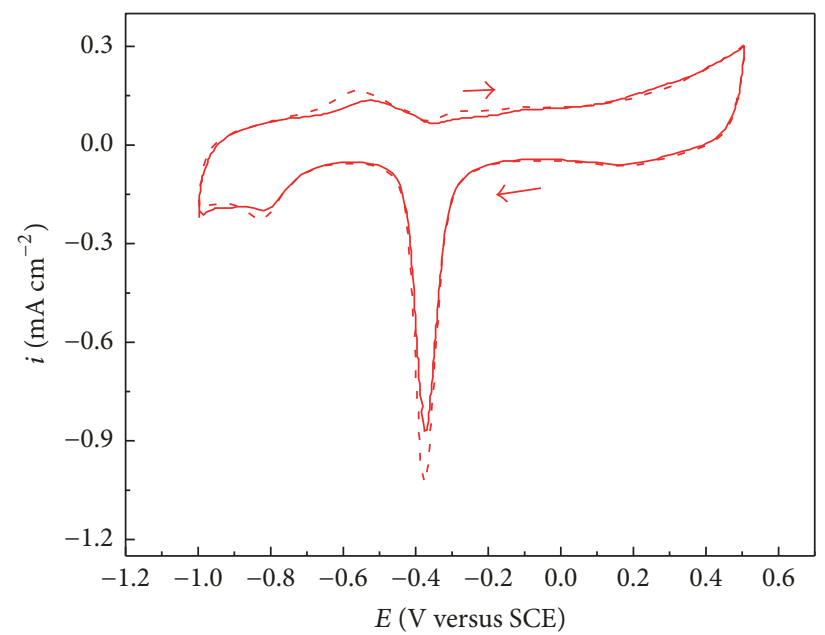

(b)

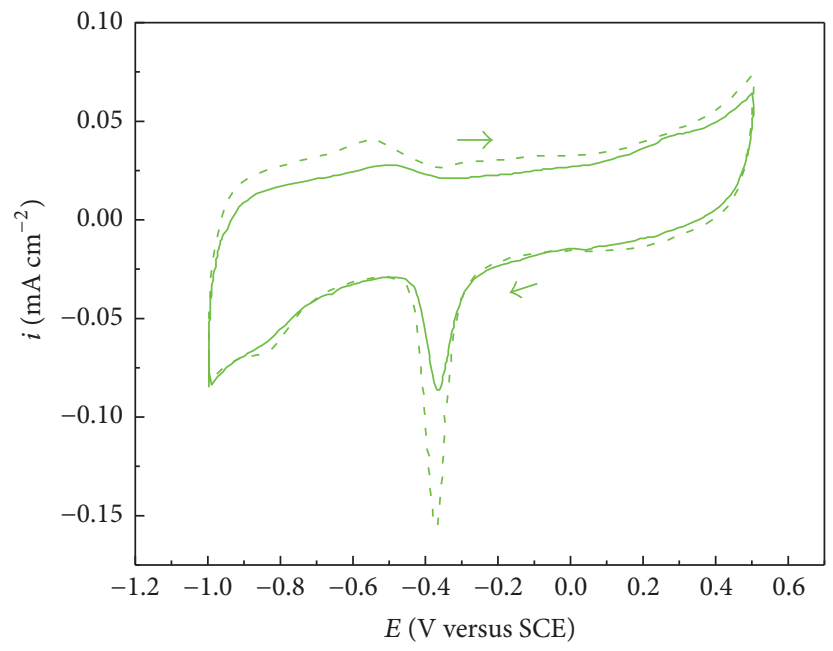

(c)

Figure 3: Cyclic voltammograms for the (a) PdAg-a, (b) PdAg-b, and (c) PdAg-c catalyst in $1 \mathrm{M} \mathrm{KOH}$ at room temperature. The solid line indicates the first cycle while the dashed line corresponds to cycle ten.

and $\mathrm{PdO}$ reduction signals was observed on the three catalysts. However, the peaks associated with the oxidationreduction of silver in the PdAg-a catalyst decreased during the first 10 cycles, probably due to the removal of $\mathrm{Ag}$ atoms from the catalyst surface. This indicated that the silver on the surface of this material has a weak anchorage with the rest of the nanoparticle.

The electrochemical active surface area (ECSA) was determined by integrating the palladium oxide reduction (zone III in Figure 3) and using the following formula [27]:

$$
\mathrm{ECSA}=\frac{Q}{Q_{\mathrm{ref}}},
$$

where $Q$ is the coulombic charge resulting from the integration of reduction peak III and $Q_{\text {ref }}$ is the electric charge necessary for the reduction of a $\mathrm{PdO}$ monolayer and is equal to $405 \mu \mathrm{C} \mathrm{cm}^{-2}$ [27]. The ECSAs of the PdAg-a, PdAg-b, and PdAg-c electrocatalysts are shown in Table 2. These results
TABle 2: Electrochemical active surface areas for PdAg-a, PdAg-b, and PdAg-c electrocatalysts after ten cycles.

\begin{tabular}{lc}
\hline Electrocatalyst & ECSA $\left(\mathrm{cm}^{2} / \mathrm{mg}\right)$ \\
\hline PdAg-a & 33.3 \\
PdAg-b & 124 \\
PdAg-c & 17.3 \\
\hline
\end{tabular}

were used to normalize the electric currents obtained by the cyclic voltammetry and the chronoamperometry in the presence of ethanol. A lower electroactive area was noticed in the highest temperature PdAg-c catalyst compared to the PdAg-a and PdAg-b catalysts. This result was associated with the larger particle and crystal sizes in this catalyst when compared to the others. According to XRD and TEM results, a high electroactive area would be expected in the lowest temperature catalyst (PdAg-a) due to its smaller particle and crystal sizes. However, the ECSA was the smallest of the three 


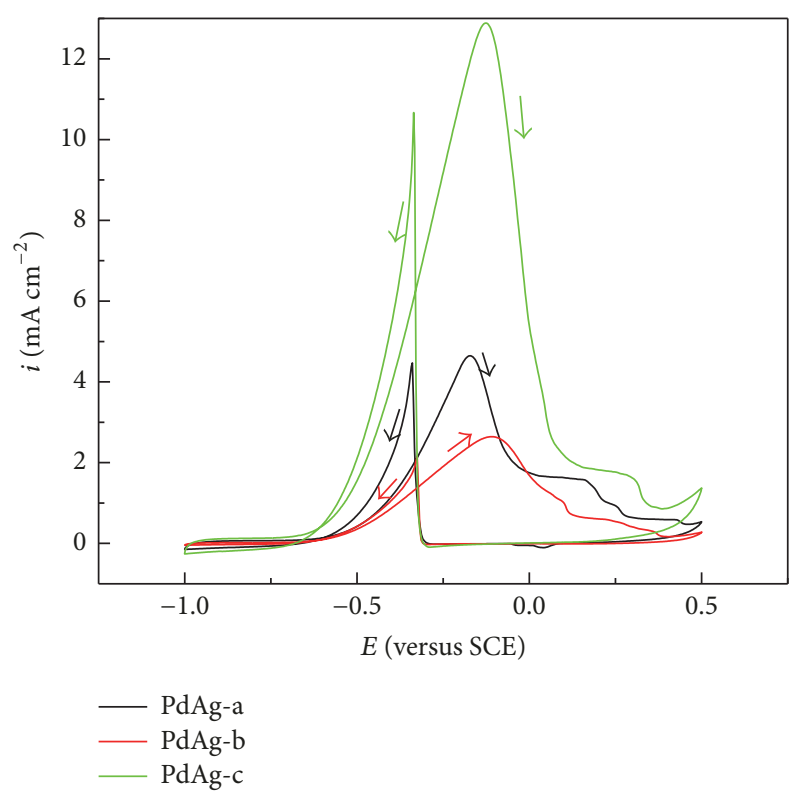

FIgUre 4: Cyclic voltammograms for the PdAg-a, PdAg-b, and PdAg-c electrocatalysts in $1 \mathrm{M} \mathrm{KOH}+1 \mathrm{M}$ ethanol solutions.

catalysts. This discrepancy was due to the high concentration of $\mathrm{Ag}$ at the surface (Figure 3), which was not considered in the ECSA calculation.

Cyclic voltammograms in the presence of ethanol correspond to the ethanol electrooxidation reaction. Figure 4 shows the voltammogram cycles of the PdAg-a, PdAg-b, and PdAg-c electrocatalysts in $1 \mathrm{M}$ ethanol $+1 \mathrm{M} \mathrm{KOH}$ solution. All voltammograms showed two characteristic peak currents: one in the anodic and the other one in the cathodic direction. In the anodic scan, the peak is associated with the oxidation of chemisorbed species derived from fresh-ethanol adsorption, while the oxidation peak in the reversed scan is related to the removal of carbon species that were not completely oxidized during the course in the positive direction. The PdAg-a catalyst $(-0.18 \mathrm{~V})$ showed the most negative oxidation potential, as well as a better thermodynamic performance compared to the PdAg-b $(-0.12 \mathrm{~V})$ and PdAg-c $(-0.13 \mathrm{~V})$ catalysts. This effect could be associated with the higher nanobar content in this catalyst (see TEM results) which exposes $\operatorname{Pd}\left(\begin{array}{lll}2 & 0 & 0\end{array}\right)$ faces that favor the adsorption and oxidation of ethanol at low potentials [28]. In kinetic terms, it was observed that the maximum current densities for the PdAg-a, PdAg-b, and PdAg-c catalysts were 4.6, 2.6, and $12.9 \mathrm{mAcm}^{-2}$, respectively. The current densities of the PdAg-a and PdAg-b catalysts showed low values, while the higher temperature catalyst (PdAg-c) showed the best kinetic performance. Table 3 shows the results reported for the $\mathrm{PdAg}$ and other representative catalytic systems for comparative purposes. A similar catalytic activity in terms of onset potential (OP) and maximum peak potential (MPP) was observed in the three catalysts in comparison to the PdAg systems in Table $3(\mathrm{OP}=-0.75 \mathrm{~V}$ versus SCE or -0.649 versus $\mathrm{Hg} / \mathrm{HgO} 1 \mathrm{M} \mathrm{NaOH}$; $\mathrm{MPP}=$ $-0.079,-0.019$, and $-0.029 \mathrm{~V}$ versus $\mathrm{Hg} / \mathrm{HgO} 1 \mathrm{M} \mathrm{NaOH}$ for PdAg-a, PdAg-b, and PdAg-c catalysts, resp.). However, the peak current for the PdAg-c catalyst is higher than practically all the catalysts presented in the table (with the exception of the PdAg nanowires).

According to Oliveira et al., there is a difference of $0.2 \AA$ between the lattice parameter of pure $\mathrm{Pd} / \mathrm{C}$ and $\mathrm{Ag} / \mathrm{C}$ catalysts. They reported that the lattice parameter of $\mathrm{Pd}$ increases linearly with the Ag concentration in the PdAg alloy obtained by electroless method [19]. The highest electroactivity for ethanol electrooxidation was observed in the Pd79Ag21 catalyst with $a_{\mathrm{PdAg}}=3.925 \AA$, with a lattice expansion of $a_{\mathrm{PdAg}}-a_{\mathrm{Pd}}=\Delta a=0.035 \AA$ [19]. In addition, the lineal increase of the lattice parameter with Ag concentration has also been reported by $\mathrm{Li}$ et al. for PdAg catalysts synthesized by impregnation-reduction with the hydrogen gas method [18]. A "volcano" behavior of the catalytic activity in terms of current density versus lattice parameter was reported, with a maximum activity when the Ag content was within 25-33\%, which corresponds to a lattice expansion in the range of $\Delta a=0.04-0.05 \AA$ [18]. Taking into account the fact that the concentration of $\mathrm{Ag}$ remained constant (at 20\%) in all the syntheses performed in this study, the results showed that manipulating the reaction temperature allowed modifying the lattice expansion of $\mathrm{PdAg}$ catalysts during the polyol process. The lattice expansion obtained was $\Delta a=0.045$, 0.046, and $0.052 \AA$, for the PdAg-a, PdAg-b, and PdAg-c catalysts, respectively. Our results agree with those reported by $\mathrm{Li}$ and coworkers, as the higher activity and stability among the catalyst evaluated were close to the upper limit of lattice expansion $(0.05 \AA)$. This suggests that the lattice expansion of the PdAg catalyst is a critical parameter for the ethanol electrooxidation reaction.

This research shows that the temperature change during the catalyst synthesis brings about a different degree of interaction between $\mathrm{Pd}$ and $\mathrm{Ag}$, which causes modifications in the electroactivity of the catalysts. Based on the $d$-band center theory and the mechanism proposed by Hammer and Nørskov, deformation in the Pd-surface structure moves up the center of band $d$ of the $\mathrm{Pd}$ [29]. This promotes an increase in the concentration of $\mathrm{OH}^{-}$species over the surface of the electrocatalyst that improves the elimination of ethoxyl intermediates, thus maintaining the EOR reaction [17]. Interestingly, larger particle and crystal sizes were observed in the PdAg-c catalyst, which would suggest that the reduced performance of this catalyst is related to its small electrochemical active area. However, the higher integration of the Ag atoms into the Pd network observed by VC and XRD (in the PdAg-c catalyst) indicates that the structural modification of the $\mathrm{Pd}$ with the presence of Ag plays an important role in carrying out the EOR in alkaline medium.

Chronoamperometry tests were performed to analyze the stability of the catalysts at a potential of $-0.3 \mathrm{~V}$ versus ECS. Figure 5 shows the behavior of the current density as a function of time. A noticeable decrease in current density was observed during the first seconds in the three catalysts. Subsequently, the current density presented a gradual decrease for all the catalysts. This behavior indicated that the current density followed the Cottrell equation. According to this model, the active sites are initially free of adsorbed/oxidized 


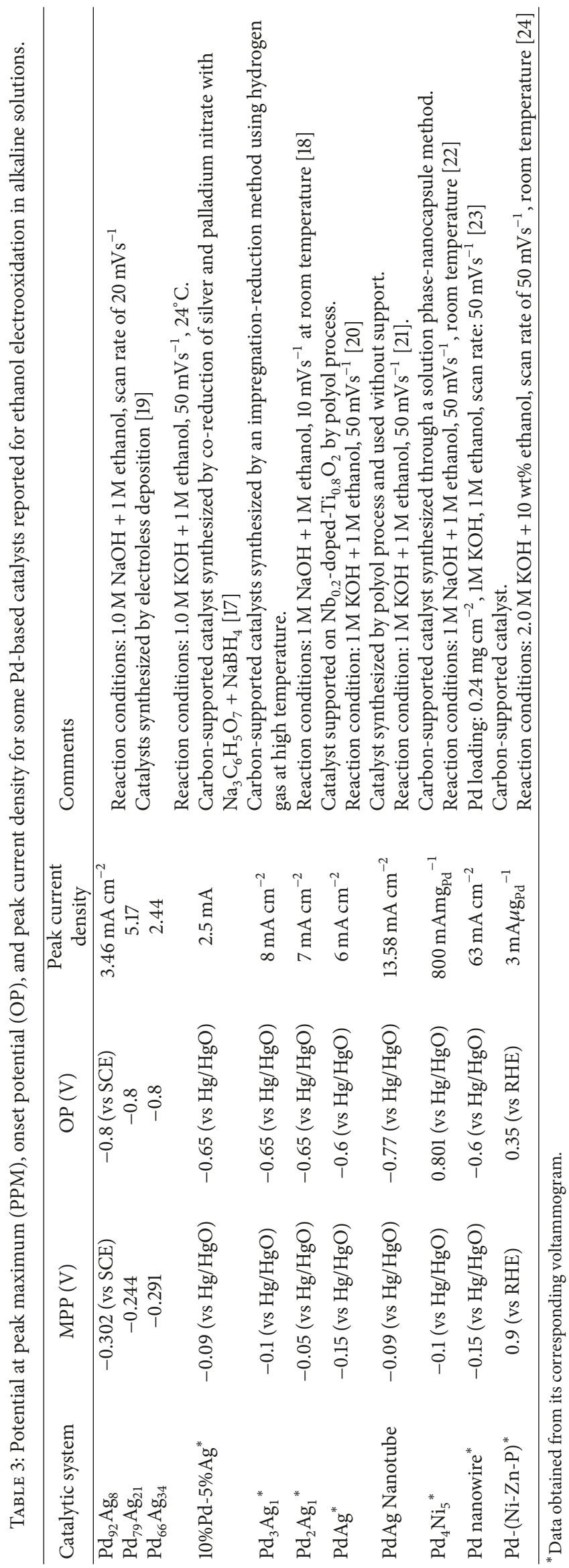




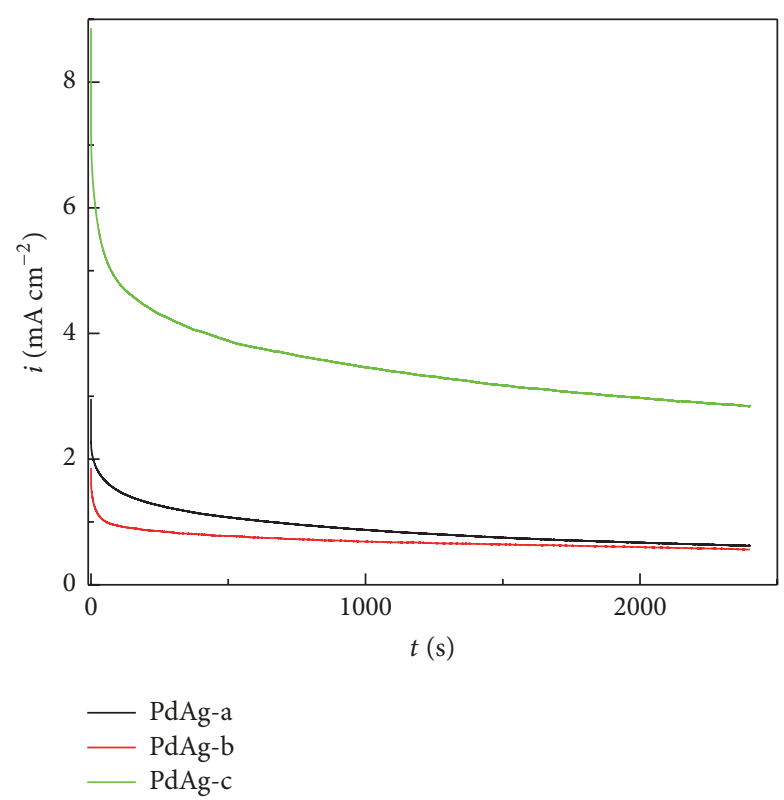

Figure 5: Chronoamperometry results for PdAg-a, PdAg-b, and PdAg-c electrocatalysts $1 \mathrm{M} \mathrm{KOH}+1 \mathrm{M}$ ethanol solutions at $-0.3 \mathrm{~V}$ versus SCE.

ethanol molecules. As the reaction takes place, the rate of adsorption of a new ethanol molecule will depend on the availability of active sites in the catalyst. This makes the process governed by the diffusion of reagents and products. It can be observed that the catalysts produce different current densities at the start of the perturbation, where the PdAg-c catalyst holds the highest value and is followed by the PdAg$a$ and PdAg-b catalysts. The PdAg-b catalyst showed a faster decrease in the current density with respect to the other catalysts studied. The PdAg-c electrocatalyst maintained the highest current density (about $2.5 \mathrm{~mA} \mathrm{~cm}^{-2}$ ) after $240 \mathrm{~s}$ at $-0.3 \mathrm{~V}$ versus ECS, indicating that this catalyst was the most stable under these reaction conditions. The PdAg-b electrocatalyst was the least stable as its current density was the lowest after the same reaction time. This indicates that the catalyst synthesized at a higher temperature is not only the most active (according to VC), but also the most stable.

\section{Conclusions}

The ethanol electrooxidation reaction on PdAg catalysts was analyzed as a function of the reduction temperature in the polyol process. The increase of the reduction temperature favors the growth of the particle and crystal sizes due to the increase of the reduction kinetics of the precursors. The angular displacement of the diffraction pattern was greater when the reduction temperature increased. This behavior points to a high interaction between palladium and silver. The maximum current density for the PdAg-a, PdAg-b, and PdAg-c electrocatalysts was 4.6, 2.6, and $12.9 \mathrm{~mA} \mathrm{~cm}^{-2}$, respectively. The PdAg-c catalyst maintained the highest current density after $40 \mathrm{~min}$ at $-0.3 \mathrm{~V}$ versus SCE. Finally, the catalyst synthesized at a higher temperature $(\mathrm{PdAg}-\mathrm{c})$ showed higher electrocatalytic activity in terms of the maximum current density, as well as a higher catalytic stability under the reaction conditions used. The improvement in catalytic performance was associated with the higher interaction between PdAg observed by XRD and cyclic voltammetry studies.

\section{Conflicts of Interest}

The authors declare that they have no conflicts of interest.

\section{Acknowledgments}

R. Carrera thanks Lourdes Palma Tirado (Center for Neurosciences, UNAM, Juriquilla) for the support with the TEM analysis and the SIP-IPN for the financial support through Project 20161376. D. D. Hernandez thanks CONACYT for the BS Grant no. 337852. The authors acknowledge CNMNIPN for the experimental support and thank M. T. Carrillo from the University of Guanajuato for the revision of the manuscript.

\section{References}

[1] C. Song, "Fuel processing for low-temperature and hightemperature fuel cells: Challenges, and opportunities for sustainable development in the 21st century," Catalysis Today, vol. 77, no. 1-2, pp. 17-49, 2002.

[2] M. Z. F. Kamarudin, S. K. Kamarudin, M. S. Masdar, and W. R. W. Daud, "Review: Direct ethanol fuel cells," International Journal of Hydrogen Energy, vol. 38, no. 22, pp. 9438-9453, 2013.

[3] L. Jiang and G. Sun, "Fuel cells-direct alcohol fuel cells-direct ethanol fuel cells," in Encyclopedia of Electrochemical Power Sources, pp. 390-401, 2009.

[4] B. Hoyos, El mecanismo de la electro-oxidación de metanol y etanol Una revisión bibliográfica. Dyna 137, 10-22, 2002.

[5] S. Q. Song, Y. Wang, and P. K. Shen, "Thermodynamic and kinetic considerations for ethanol electrooxidation in direct ethanol fuel cells," Chinese Journal of Catalysis, vol. 28, no. 9, pp. 752-754, 2007.

[6] E. Antolini, "Palladium in fuel cell catalysis," Energy \& Environmental Science, vol. 2, no. 9, pp. 915-931, 2009.

[7] E. Antolini and E. R. Gonzalez, "Alkaline direct alcohol fuel cells," Journal of Power Sources, vol. 195, no. 11, pp. 3431-3450, 2010.

[8] B. Coq and F. Figueras, "Bimetallic palladium catalysts: Influence of the co-metal on the catalyst performance," Journal of Molecular Catalysis A: Chemical, vol. 173, no. 1-2, pp. 117-134, 2001.

[9] Y. Wang, T. S. Nguyen, X. Liu, and X. Wang, "Novel palladiumlead $(\mathrm{Pd}-\mathrm{Pb} / \mathrm{C})$ bimetallic catalysts for electrooxidation of ethanol in alkaline media," Journal of Power Sources, vol. 195, no. 9, pp. 2619-2622, 2010.

[10] D. Y. Kim, S. W. Kang, K. W. Choi et al., “Au@Pd nanostructures with tunable morphologies and sizes and their enhanced electrocatalytic activity," CrystEngComm, vol. 15, no. 35, pp. 71137120,2013

[11] L. E. Walle, H. Gronbeck, V. R. Fernandes et al., "Surface composition of clean and oxidized Pd 75Ag 25(100) from 
photoelectron spectroscopy and density functional theory calculations," Surface Science, vol. 606, no. 23-24, pp. 1777-1782, 2012.

[12] C.-L. Lee, H.-P. Chiou, K.-C. Chang, and C.-H. Huang, "Carbon nanotubes-supported colloidal Ag-Pd nanoparticles as electrocatalysts toward oxygen reduction reaction in alkaline electrolyte," International Journal of Hydrogen Energy, vol. 36, no. 4, pp. 2759-2764, 2010.

[13] D. Chen, P. Cui, H. He, H. Liu, and J. Yang, "Highly catalytic hollow palladium nanoparticles derived from silver@silverpalladium core-shell nanostructures for the oxidation of formic acid," Journal of Power Sources, vol. 272, pp. 152-159, 2014.

[14] A. J. Armenta-González, R. Carrera-Cerritos, M. GuerraBalcázar, L. G. Arriaga, and J. Ledesma-García, "Comparative study of carbon-supported Pd and PdAg catalysts synthesised by the polyol process and reverse micelles methods," Journal of Applied Electrochemistry, vol. 45, no. 1, pp. 33-41, 2015.

[15] R. Carrera-Cerritos, C. Ponce De León, J. Ledesma-García, R. Fuentes-Ramírez, and L. G. Arriaga, "Full factorial design applied to the synthesis of Pd-Ag nanobars by the polyol method and the perspective for ethanol oxidation," RSC Advances, vol. 4, no. 32, pp. 16632-16640, 2014.

[16] J. Liu, H. Zhou, Q. Wang, F. Zeng, and Y. Kuang, "Reduced graphene oxide supported palladium-silver bimetallic nanoparticles for ethanol electro-oxidation in alkaline media," Journal of Materials Science, vol. 47, no. 5, pp. 2188-2194, 2012.

[17] S. T. Nguyen, H. M. Law, H. T. Nguyen et al., "Enhancement effect of $\mathrm{Ag}$ for Pd/C towards the ethanol electro-oxidation in alkaline media," Applied Catalysis B: Environmental, vol. 91, no. 1-2, pp. 507-515, 2009.

[18] G. Li, L. Jiang, Q. Jiang, S. Wang, and G. Sun, "Preparation and characterization of PdxAgy/C electrocatalysts for ethanol electrooxidation reaction in alkaline media," Electrochimica Acta, vol. 56, no. 22, pp. 7703-7711, 2011.

[19] M. C. Oliveira, R. Rego, L. S. Fernandes, and P. B. Tavares, "Evaluation of the catalytic activity of Pd-Ag alloys on ethanol oxidation and oxygen reduction reactions in alkaline medium," Journal of Power Sources, vol. 196, no. 15, pp. 6092-6098, 2011.

[20] S. T. Nguyen, Y. Yang, and X. Wang, "Ethanol electro-oxidation activity of $\mathrm{Nb}$-doped-TiO 2 supported $\mathrm{PdAg}$ catalysts in alkaline media," Applied Catalysis B: Environmental, vol. 113-114, pp. 261270, 2012.

[21] C. Peng, W. Yang, E. Wu et al., "PdAg alloy nanotubes with porous walls for enhanced electrocatalytic activity towards ethanol electrooxidation in alkaline media," Journal of Alloys and Compounds, vol. 698, pp. 250-258, 2017.

[22] Z. Zhang, L. Xin, K. Sun, and W. Li, "Pd-Ni electrocatalysts for efficient ethanol oxidation reaction in alkaline electrolyte," International Journal of Hydrogen Energy, vol. 36, no. 20, pp. 12686-12697, 2011.

[23] C. Xu, H. Wang, P. K. Shen, and S. P. Jiang, "Highly ordered Pd nanowire arrays as effective electrocatalysts for ethanol oxidation in direct alcohol fuel cells," Advanced Materials, vol. 19, no. 23, pp. 4256-4259, 2007.

[24] C. Bianchini and P. K. Shen, "Palladium-based electrocatalysts for alcohol oxidation in half cells and in direct alcohol fuel cells," Chemical Reviews, vol. 109, no. 9, pp. 4183-4206, 2009.

[25] J. Zeng, C. Zhu, J. Tao et al., "Controlling the nucleation and growth of silver on palladium nanocubes by manipulating the reaction kinetics," Angewandte Chemie International Edition, vol. 51, no. 10, pp. 2354-2358, 2012.
[26] Y. Xiong, H. Cai, B. J. Wiley, J. Wang, M. J. Kim, and Y. Xia, "Synthesis and mechanistic study of palladium nanobars and nanorods," Journal of the American Chemical Society, vol. 129, no. 12, pp. 3665-3675, 2007.

[27] S. Trasatti and O. A. Petrii, "Real surface area measurements in electrochemistry," Pure Appl Chem, vol. 63, pp. 711-734, 1991.

[28] Z. X. Liang, T. S. Zhao, J. B. Xu, and L. D. Zhu, "Mechanism study of the ethanol oxidation reaction on palladium in alkaline media," Electrochimica Acta, vol. 54, no. 8, pp. 2203-2208, 2009.

[29] B. Hammer and J. K. Nørskov, "Theoretical surface science and catalysis-calculations and concepts," Advances in Catalysis, vol. 45, no. C, pp. 71-129, 2000. 


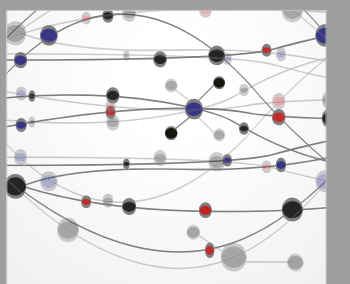

The Scientific World Journal
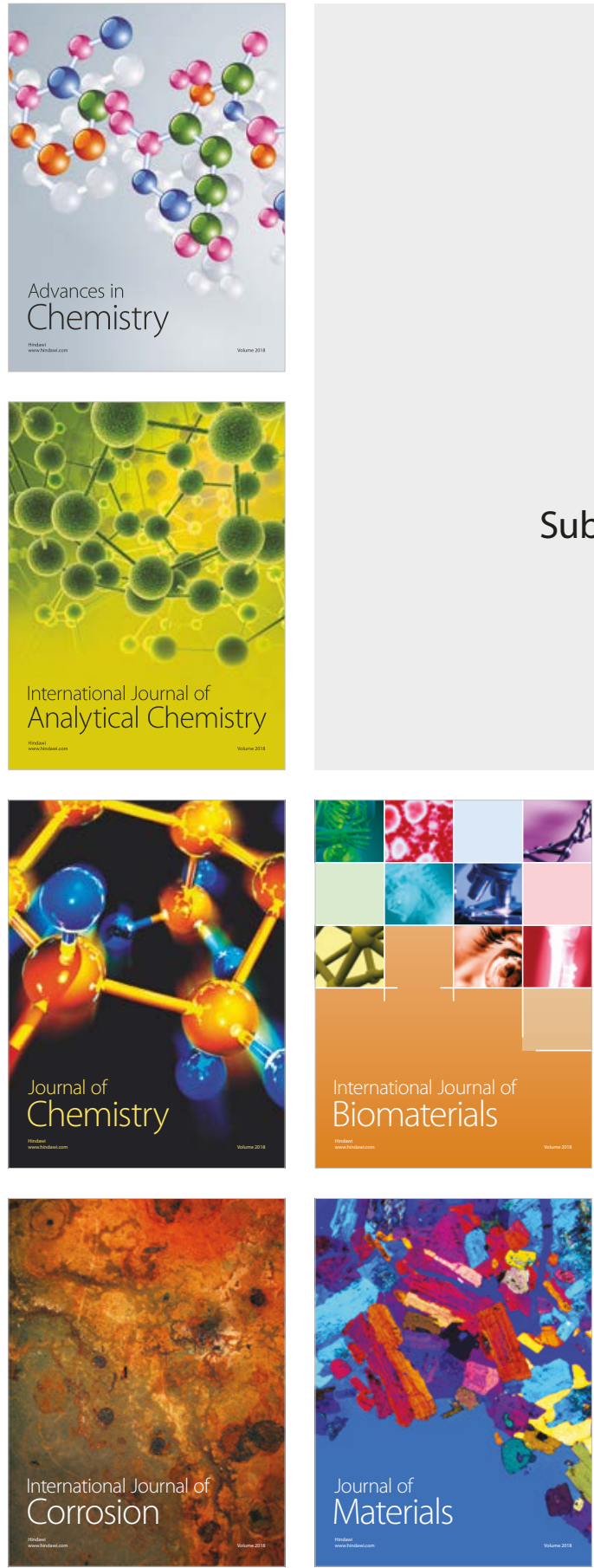

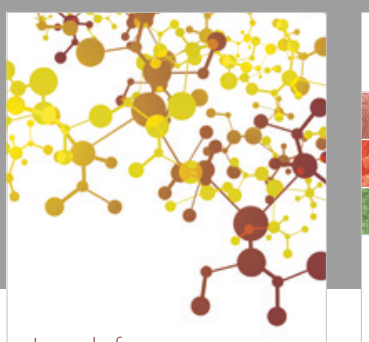

Journal of

Applied Chemistry
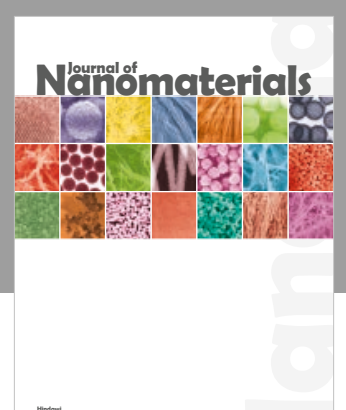

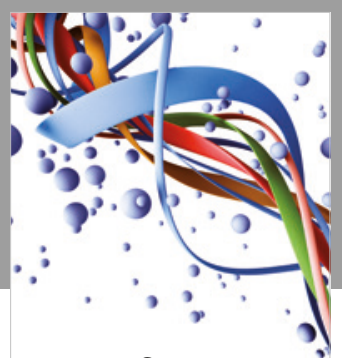

Scientifica

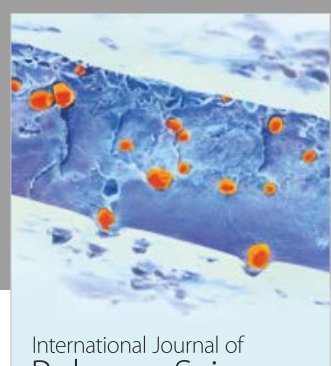

Polymer Science

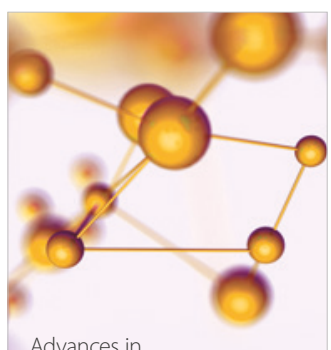

Physical Chemistry
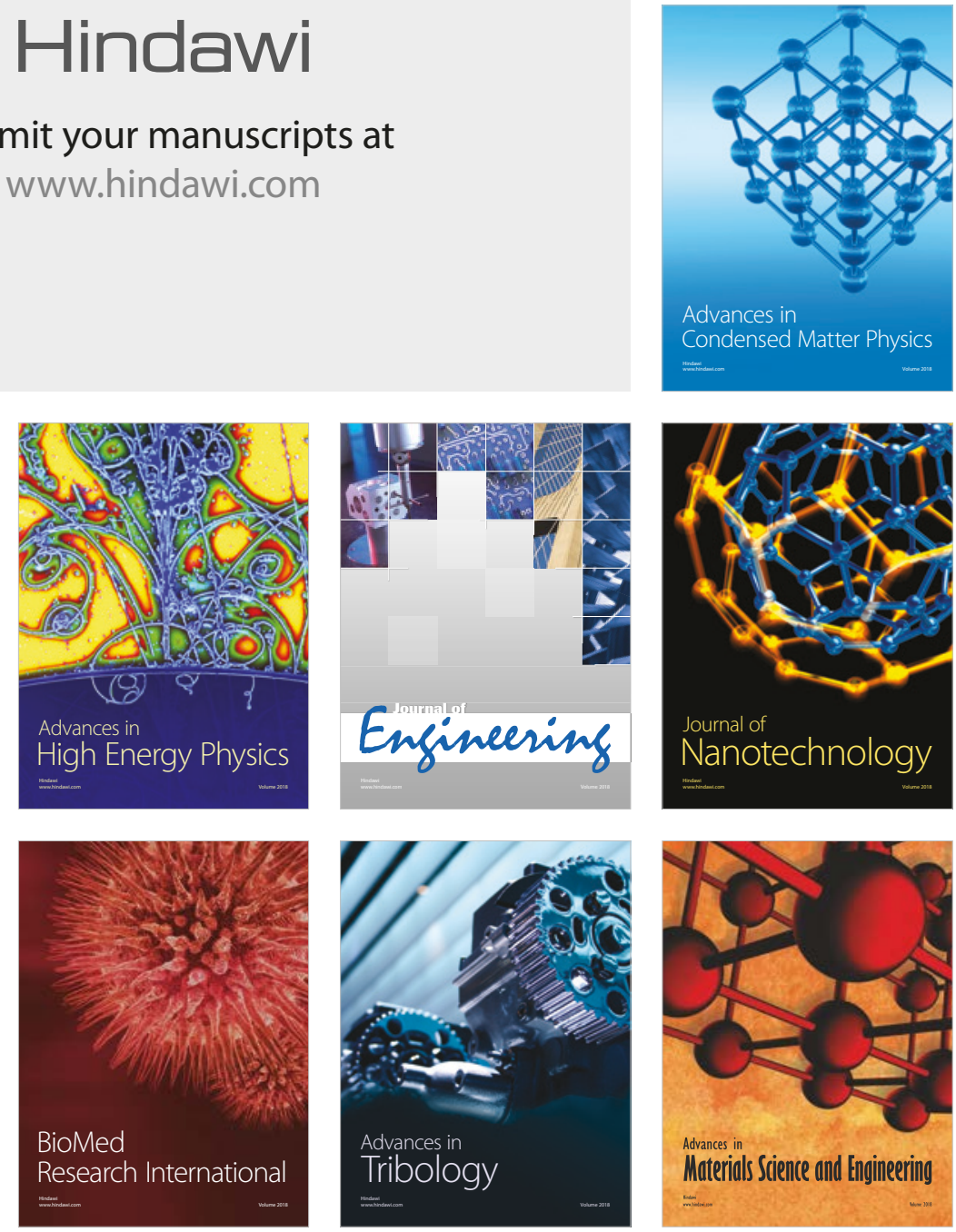